\title{
CT-Guided Percutaneous Spine Biopsy in Suspected Infection or Malignancy: A Study of 214 Patients
}

\section{CT-gesteuerte perkutane Wirbelsäulenpunktionen bei Verdacht auf Infektion oder Tumor: Eine Studie mit 214 Patienten}

Authors

Affiliations
J. Rehm', S. Veith ${ }^{1}$, M. Akbar², H. U. Kauczor ${ }^{1}$, M. A. Weber ${ }^{1}$

Institute of Diagnostic and Interventional Radiology, Universitiy of Heidelberg, Germany

Department of Orthopaedic Surgery and Rehabilitation Medicine, University of Heidelberg, Germany
Key words

- biopsy

- CT-guided

- spine

- percutaneous

spondylodiscitis

- tumor

received 28.6.2016

accepted $\quad 18.8 .2016$

Bibliography

Dol http://dx.doi.org/

10.1055/s-0042-116233

Published online: 2016

Fortschr Röntgenstr 2016; 188:

1156-1162 @ Georg Thieme

Verlag KG Stuttgart · New York .

ISSN 1438-9029

\section{Correspondence \\ Dr. Johannes Rehm}

Diagnostische und

Interventionelle Radiologie,

UniversitätsKlinikum Heidelberg

INF 110

69120 Heidelberg

Germany

Tel.: ++49/6221/5635136

Fax: ++49/6221/56 5420

johannes.rehm@med.uni-

heidelberg.de

\section{Zusammenfassung}

\section{$\nabla$}

Ziel: Retrospektive Bestimmung der Effektivität und Genauigkeit von CT-gesteuerten perkutanen Biopsien von malignen und entzündlichen Veränderungen der Wirbelsäule und Bestimmung der Reliabilität der prä-interventionell durchgeführten CT- und MRT-Bildgebung.

Material und Methoden: 214 Patienten mit Knochenläsionen der Wirbelsäule, welche suspekt für Malignität oder Entzündung waren, erhielten eine CT-gesteuerte Biopsie zur histologischen und/oder mikrobiologischen Analyse. Bei 128/214 Patienten wurden Proben zur histologischen, bei 17/214 Patienten zur mikrobiologischen und bei 69/214 Patienten wurden jeweils 2 Proben eingesandt. Retrospektiv wurde die diagnostische Genauigkeit und die Sensitivität/Spezifität der prä-interventionellen Bildgebung (CT und MRT) bestimmt. Außerdem wurde der Einfluss der Biopsie auf das weitere Patientenmanagement ermittelt.

Ergebnisse: Die Genauigkeit lag bei 94,4\% für die histopathologische und bei $97,7 \%$ für die mikrobiologische Analyse. In $25 \%$ der Fälle konnte bei der mikrobiologischen Analyse ein ursächlicher Erreger nachgewiesen werden, der Keimnachweis wurde dabei nicht signifikant durch eine vor der Biopsie durchgeführte Antibiotikatherapie beeinflusst. Die Sensitivität/Spezifität der prä-interventionellen Bildgebung lag in Bezug auf eine suspizierte maligne Läsion bei $69 \% / 78 \%$. Bei Verdacht auf eine Infektion lag die Sensitivität/Spezifität der prä-interventionellen Bildgebung bei $81 \% / 44 \%$. In $52 \%$ der Fälle resultierte das Ergebnis der Biopsie in einem veränderten Patientenmanagement.

Schlussfolgerung: Die perkutane CT-gesteuerte Wirbelsäulenpunktion ist eine nützliche und zuverlässige diagnostische Methode mit aber relativ geringer Rate an Keimnachweisen im Falle einer Infektion.

\section{Abstract \\ $\nabla$}

Purpose: To retrospectively determine the effectiveness and accuracy of CT-guided percutaneous biopsy of malignant and inflammatory bone lesions of the spine and to assess the reliability of pre-biopsy CT and MRI.

Materials and Methods: 214 patients with lesions of the spine, which were suspicious either for being malignant or inflammatory, underwent CT-guided biopsy for pathological and/or microbiological detection. Biopsy samples were sent for histological examination in 128/214 patients, for microbiological analysis in 17/214 patients and for both analyses in 69/214 patients. Retrospectively, the diagnostic accuracy and sensitivity/specificity of the pre-interventional imaging (CT and MRI) were determined. In addition, the influence of the biopsy on subsequent patient management was assessed.

Results: The accuracy was $94.4 \%$ for histopathological analysis and $97.7 \%$ for microbiological analysis. In $25 \%$ of cases the microbiological analysis revealed an underlying pathogen that was not significantly affected by pre-biopsy antibiotic therapy. The sensitivity/specificity of the pre-biopsy crosssectional imaging concerning suspected malignancy was $69 \% / 78 \%$. For suspected infection, the sensitivity/specificity of pre-biopsy imaging was $81 \%$ / $44 \%$. In $52 \%$ of all cases, the biopsy result changed subsequent patient management.

Conclusion: Percutaneous CT-guided spine biopsy is a useful and reliable diagnostic procedure to establish a definitive diagnosis but with a relatively low yield of microorganisms in the case of infection.

Key Points:

-CT-guided spine biopsy is an accurate and reliable procedure in case of infection and tumour.

- The results of the CT-guided spine biopsy have a significant influence on the subsequent patient management. 
Kernaussagen:

> CT-gesteuerte Wirbelsäulenpunktionen stellen eine akkurate und verlässliche diagnostische Methode im Falle einer Infektion oder eines Tumors dar.

> Die Ergebnisse der CT-gesteuerten Wirbelsäulenpunktion haben einen signifikanten Einfluss auf das weitere Patientenmanagement.

- Im Falle einer Infektion ist Rate an positiven Keimnachweisen mäßig jedoch nicht signifikant beeinflusst durch eine vorangegangene Antibiotikatherapie.
Pathogen recovery-rate in case of infection is moderate but not significantly affected by prebiopsy antibiotic therapy.

Citation Format:

> Rehm J, Veith S, Akbar M etal. CT-Guided Percutaneous Spine Biopsy in Suspected Infection or Malignancy: A Study of 214 Patients. Fortschr Röntgenstr 2016; 188: 1156-1162

\section{Introduction}

\section{$\nabla$}

Spine biopsies are carried out in the case of a suspicious bone lesion detected when patients are screened for malignancy, infection or back pain presenting with so-called red flags using computed tomography (CT) or magnetic resonance imaging (MRI). Although radiological imaging techniques are known to have a good predictive value, a histological or microbiological examination is often required to confirm the correct diagnosis, to identify microbes and to plan further treatment. For this purpose an accurate biopsy and appropriate specimen sampling are fundamental. Although open biopsy is the gold standard in musculoskeletal lesions providing adequate specimens, performing such an open biopsy in vertebral lesions is associated with a significant risk of complications because most of the lesions are relatively inaccessible and adjacent to vital structures $[1,2]$. Since CT-guided biopsy is considered a safe and accurate method to define the diagnosis, it has become the procedure of choice [3-5]. Compared to open biopsy there is also less risk of tumor spread, infection and wound problems. In addition, it is fast, economical and applicable to outpatients or day hospital patients as general anesthesia is rarely required [6].

The purpose of this study was to assess the diagnostic accuracy of spine biopsies performed at our institution and to evaluate the impact on the further therapy and management of percutaneous CT-guided spine biopsy in the case of suspected malignancy or infection. In addition, the role of pre-biopsy cross-sectional imaging was assessed.

\section{Materials and methods}

This retrospective study was approved by our local institutional review board. A search of our institutional electronic medical record database from April 2003 to September 2014 was performed for all patients who underwent CT-guided biopsy of the spine in the case of bone lesion suspicious of malignancy or infection. The 214 biopsies were performed in 122 male and 92 female patients ranging in age from 12 to 91 years (average age, 63 years). All available CT (201/214) and MRI examinations (183/214) performed prior to biopsy were reviewed by 2 radiologists in consensus. After interdisciplinary individual case discussion, CT-guided intervention was indicated. All suspicious lesions, which showed suspicious signal intensity in MRI (defined as low signal intensity on T1-weighted images and high signal intensity on fat-suppressed T2-weighted images together with contrast enhancement) or bone destruction in CT (defined as pathological lytic or blastic bone marrow replacement and cortical destruction) were indicated for biopsy. The CT criteria for infection (e.g. spondylodiscitis) were irregularity or illdefined endplates, disk space narrowing without vacuum phenomenon and paravertebral abscess formation. The MRI criteria for in- fection were increased diffuse signal intensity on T2-weighted images in the vertebral body, the disk space or the paravertebral soft tissue with corresponding decreased signal intensity on T1-weighted images and infection-like contrast enhancement. In addition, a diminished margin between disk and endplate and paravertebral abscess indicated an infection. The lesions were divided into lesions that were suspicious for being malignant $(n=94)$ and lesions that were suspicious for being inflammatory/infectious $(n=52)$. In some cases, the image morphology was not clear $(n=68)$.

In the case of more than one lesion, the biopsy sample was taken at the most easily approachable level with the best chance for collection of sufficient material. The access to the bone lesion was planned and the patient was transferred to the CT gantry in the same position. Using a standard CT guide light, indelible marks were made on the patient's skin over the biopsy site. Before the procedure adequate coagulation was ensured. Therefore, the platelet count $(>50 / \mathrm{nl})$, activated partial thromboplastin time $(<50 \mathrm{sec})$ and INR ( $>1.5$ ) were determined. In the case of coagulopathy, coagulation was sufficiently corrected before puncture. CT-guided biopsy was performed on a Somatom Emotion scanner, Somatom Definition scanner or on a Volume Zoom scanner (all Siemens Healthcare, Germany). A thin-slice planning CT scan was performed with the patient in a prone position and multiplanar reconstructions were used to non-traumatically position the biopsy needle. Depth, distance and angle measurements were based on computer calculations performed by the CT scanner. 208 procedures were performed under moderate IV sedation using $15 \mathrm{mg}$ piritramide (Dipidolor, Hameln, Germany) and 1.25 - $2.5 \mathrm{mg}$ midazolam (Dormicum, Hameln, Germany) with continuous monitoring of vital signs. 6 patients underwent general anesthesia because of age, personal preference or inability to maintain a prone position. Aseptic preparation of the skin overlying the biopsy needle trajectory was performed and consecutive local anesthesia with $5 \mathrm{ml}$ carbostesin $0.5 \%$ (Astra Zeneca, Wedel, Germany) was administered. A small skin incision was made and biopsy was performed using a $3 \mathrm{~mm}$ (11G), $3.5 \mathrm{~mm}$ (9G) or $4 \mathrm{~mm}$ (8G) core needle bone biopsy system according to the width of the pedicle (SAFECUT Biopsy System, Somatex, Germany). In some cases of lytic lesions or lesions with a soft-tissue component $(n=50)$, specimens were acquired with a $2 \mathrm{~mm}$ (12G) soft-tissue coaxial biopsy needle (Bard Peripheral Vascular, Inc., USA). A 20G puncture needle was utilized when liquid or partially liquid lesions were biopsied (TERUMO Needle, TERUMO, Belgium). In a few cases ( $n=35)$, the material was acquired with a combination of these three. The correct location of the needle was confirmed by CT. All specimens were sent in a formalin-fixed manner to pathology or to microbiology immediately following the procedure. The specimens that were sent to the lab for microbiological assessment underwent GRAM stain, bacterial, fungal and mycobacterial culture. In most cases a satisfactory single core biopsy was cut in half and sent to both micro- 
biology and pathology. Specimen analysis was performed by senior physicians at our university hospital. Outpatients were discharged if no symptoms suggestive of complications had appeared after 6 hours of observation.

Demographic data, lesion data (aspect in imaging and number of lesions) and procedure data (level of puncture, duration, approach, needle used and presence of complications) were retrospectively evaluated. In addition, information at least six months after the procedure about the therapeutic consequence of the result of the puncture, such as operation, chemotherapy or no therapy, was researched. In the case of histological analysis, the results were evaluated and subdivided into malignant in the case of a primary or secondary bone tumor $(n=97)$, benign $(n=89)$ and indeterminate in cases in which the specimen was insufficient $(n=11)$. In the case of inflammation/infection, samples were analyzed similarly and subdivided into specimens in which inflammation/infection could be ruled out and/or a pathogen could be detected $(n=21)$, specimens in which inflammation/infection could not be detected $(n=63)$ and indeterminate cases in which the specimen was insufficient $(n=2)$. Cases with suspected inflammation/infection were additionally subdivided into patients who received empirical antibiotic therapy before the specimen was acquired $(n=35)$ and those who did not receive antibiotic therapy $(n=49)$. The diagnostic accuracy of the biopsy was determined by identifying the cases in which a histological or microbiological diagnosis could be ruled out.

All statistical tests were performed using SAS statistical software version 9.3 (SAS Institute Inc., North Carolina). Demographic information was described descriptively. In the case of quantitative characteristics, the arithmetical mean, standard deviation, median, minimum and maximum were calculated. For qualitative characteristics frequency tables were used. Grouped box plots were used for bivariate analysis of quantitative and qualitative characteristics. For all tests p-values $\leq 0.05$ were considered statistically significant.

\section{Results}

$\nabla$

According to the appearance in the CT scans, the lesions were divided into lytic, blastic and mixed. 193 lesions showed a lytic, 11 lesions a blastic and 10 lesions a mixed lytic-blastic appearance. Pre-biopsy imaging revealed a single lesion in 155 cases, 2 lesions in 30 cases, 3 lesions in 10 cases and 4 or more lesions in 19 cases. In total 2 procedures were performed in the cervical spine, 75 in the thoracic spine, 123 in the lumbar spine and 14 in the sacrum. The duration of the CT-guided interventions without the time needed for positioning of the patient ranged between 4 and 179 minutes (median duration: 57 minutes) and depended on the anatomical level ( $\bullet$ Table 1, $\bullet$ Fig. 1). 208 pro-

Table 1 Summary of the location of the performed punctures and the mean duration of the interventions according to the anatomical level.

Tab. 1 Zusammenfassung der Lokalisation der durchgeführten Punktionen und der Mittelwert der Interventionsdauer in Abhängigkeit von der Lokalisation.

\begin{tabular}{|lcc|}
\hline level of puncture & total (n) & mean duration (min) \\
\hline cervical spine & $2(0.9 \%)$ & 103.5 \\
\hline thoracic spine & $75(35.1 \%)$ & 64.9 \\
\hline lumbar spine & $123(57.5 \%)$ & 59.9 \\
\hline sacrum & $14(6.5 \%)$ & 55.0 \\
\hline
\end{tabular}

cedures were performed in moderate IV sedation and 6 patients underwent general anesthesia as described above.

The transpedicular approach was performed in 158/214 patients and the posterolateral approach was chosen in 56/214 patients ( 0 Fig. 2, 3). In most cases (105/214), the $4.0 \mathrm{~mm}$ biopsy system was used. The $3.0 \mathrm{~mm}$ system was used in only $5 / 214$ cases ( $\bullet$ Table 2 ). 208 patients showed no biopsy-related complications. 5 patients reported pain for 1 - 3 days, which could be controlled with NSAIDS or low-potency opioids (piritramide or pethidine). One patient reported transient paresis, which disappeared during the 6 hours of postinterventional observation. Specimens were sent only for histopathological analysis in 128 cases, only for microbiological analysis in 17 cases and for histopathological and microbiological analysis in 69 cases.

The performed CT-guided biopsy resulted in a histological diagnosis (material was sufficient and appropriate to make a diagnosis) in 186/197 cases (accuracy: 94.4\%). In microbiological analysis the material was sufficient and appropriate to make a diagnosis in 84/ 86 cases (accuracy: 97.7\%). In the non-diagnostic biopsies, the amount of sample tissue was insufficient with respect to either amount or quality. There was no significant difference between the accuracy rate and anatomical site. In addition, no significant difference in the accuracy rate could be detected with regard to the size of the used biopsy system and the used CT-guided access. In the case of suspected infection, causative pathogens were detected in $21 / 84$ microbiological analyses (success rate $=25 \%$ ). The most common were staphylococci $(\mathrm{n}=9)$ and enterobacteriaceae $(n=5)$ ( $\diamond$ Table 3). Patients with lesions suspicious for inflammation/infection were subdivided into those who received antibiotic therapy $(n=35)$ and those who did not receive prior antibiotic therapy $(n=49)$. If antibiotic therapy was not applied before biopsy, the success rate concerning detection of a causative pathogen was $27 \%$, and in case of prior antibiotic therapy the success rate was $23 \%$.

Among the patients who received pathological analysis for suspected malignancy, the most common result was a metastatic lesion $(n=56)$. Most commonly bone metastasis of prostate cancer was verified followed by breast and lung cancer ( $\bullet$ Table 4). Primary bone tumors including hematopoietic neoplasms accounted for $n=41$ ( $\diamond$ Table 5 ). The most common type in this group was multiple myeloma.

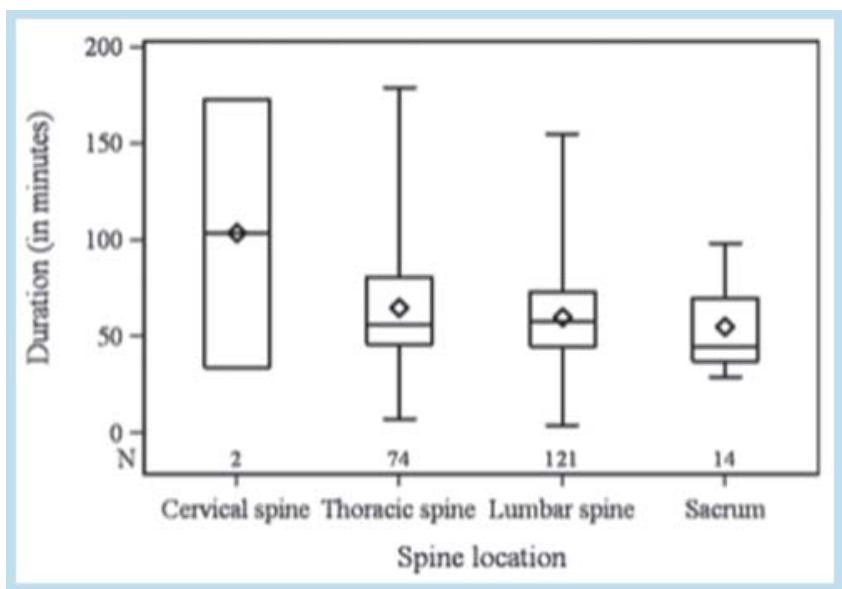

Fig. 1 Box plot of the duration of the CT-guided intervention depending on the anatomical level.

Abb. 1 Box-Plot der Dauer der CT-gesteuerten Intervention in Abhängigkeit von der Höhe der Punktion. 

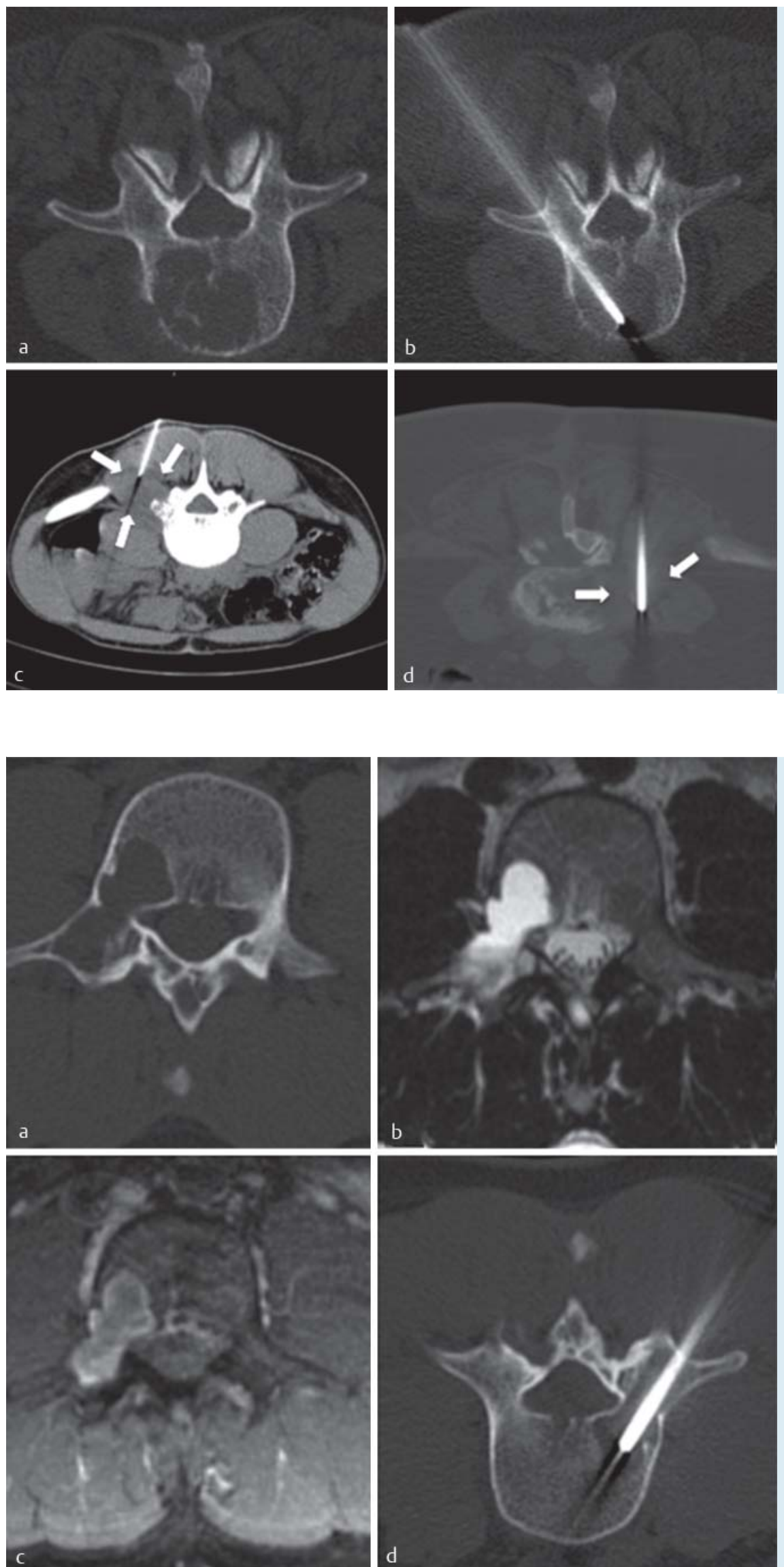

Fig. 2 a-b Transpedicular approach performed in a patient with an osteolytic lesion of the lumbar spine. c Posterolateral approach of a liquid lesion of the paravertebral tissue (arrows) in the case of suspected spondylodiscitis. $\mathbf{d}$ Posterolateral approach performed in a patient with an osteolytic lesion of the lumbar spine with a large extraosseous tumor component infiltrating the left psoas muscle (arrows).

Abb. 2 a-b Transpedikulärer Zugang bei einem Patienten mit einer osteolytischen Läsion der Lendenwirbelsäule. c Posterolateraler Zugang bei einer liquiden Läsion innerhalb der paravertebralen Weichteile (Pfeile) bei suspizierter Spondylodiszitis. d Posterolateraler Zugang bei einem Patienten mit einer osteolytischen Läsion der Lendenwirbelsäule mit einer den linken Psoasmuskel infiltrierenden extraossären Tumorkomponente.

Fig. 3 a Unclear osteolytic lesion of the lumbar spine involving the right pedicle and part of the vertebral body. $\mathbf{b}$ The T2-weighted MR image shows a predominantly liquid lesion. $\mathbf{c}$ The lesion shows marginal accentuated contrast enhancement. d Biopsy was performed with a transpedicular approach. Histopathological analysis revealed an aneurysmal bone cyst.

Abb.3 a Unklare osteolytische Raumforderung der Lendenwirbelsäule, welche den rechten Pedikel und Teile des Corpus einbezieht. b Das T2-gewichtete MRT-Bild zeigt eine überwiegend liquide Raumforderung. c Die Raumforderung hat nach Kontrastmittelgabe eine randständige Anreicherung durchgeführt. $\mathbf{d}$ Die Biopsie wurde mit einen transpedikulären Zugang durchgeführt. Die histopathologische Analyse ergab eine aneurysmatische Knochenzyste. 


\begin{tabular}{|lc|}
\hline biopsy set & total (n) \\
\hline $3 \mathrm{~mm}$ bone biopsy set/3 mm bone biopsy set with soft tissue set & $5(2.3 \%) / 1(0.5 \%)$ \\
\hline $3.5 \mathrm{~mm}$ bone biopsy set/3.5 mm bone biopsy set with puncture needle & $11(5.1 \%) / 5(2.3 \%)$ \\
\hline $4 \mathrm{~mm}$ bone biopsy set/4 mm bone biopsy set with puncture needle & $105(49.1 \%) / 21(9.8 \%)$ \\
\hline soft tissue set/soft tissue set with puncture needle & $45(21.0 \%) / 8(3.7 \%)$ \\
\hline puncture needle & $13(6.1 \%)$ \\
\hline
\end{tabular}

Table 2 Summary of the biopsy systems used.

Tab. 2 Zusammenfassung der benutzten Biopsie-Systeme.
Table 3 Summary of the pathogens in the case of infection.

Tab. 3 Zusammenfassung der gewonnenen Keime im Falle einer Infektion.

\begin{tabular}{|l|l|}
\hline type of germ & total (n) \\
\hline staphylococci & 9 \\
\hline enterobacteriaceae & 4 \\
\hline escherichia coli & 3 \\
\hline aggregatibacter aphrophilus & 2 \\
\hline mycobacterium tuberculosis & 2 \\
\hline bacteroides fragilis & 1 \\
\hline
\end{tabular}

Table 4 Summary of the primary tumors of the metastatic neoplasms.

Tab. 4 Zusammenfassung der Primärtumoren im Falle einer Metastase.

\begin{tabular}{|l|l|}
\hline primary tumor of the metastatic neoplasms & total (n) \\
\hline prostate & 13 \\
\hline breast & 12 \\
\hline lung & 10 \\
\hline colon & 6 \\
\hline kidney & 2 \\
\hline liver & 2 \\
\hline bladder & 2 \\
\hline skin (melanoma) & 3 \\
\hline thyroid & 2 \\
\hline skin (basalioma) & 1 \\
\hline leiomyosarcoma & 1 \\
\hline liposarcoma & 1 \\
\hline pancreas & 1 \\
\hline
\end{tabular}

Table 5 Summary of the primary spinal neoplasms including hematopoietic neoplasms.

Tab.5 Zusammenfassung der primären Wirbelsäulentumoren inklusive hämatopoetischer Neoplasien.

\begin{tabular}{|lc|}
\hline primary neoplasms including hematopoietic neoplasms & total (n) \\
\hline chordoma & 2 \\
\hline osteoid osteoma & 1 \\
\hline aneurysmal bone cyst & 1 \\
\hline osteosarcoma & 1 \\
\hline myeloma/plasmacytoma & 28 \\
\hline lymphoma & 6 \\
\hline leukemia & 2 \\
\hline
\end{tabular}

In the case of suspected tumor/metastasis based on preinterventional imaging, histological analysis either confirmed or denied suspicion. The sensitivity of pre-biopsy imaging (CT, MRI) for suspected tumor was 69\%, 95\%-CI: [34.9-78.1] and the specificity was 78\%, 95\%-CI: [59.0 - 79.0]. In addition to pathological analysis, microbiological analysis was additionally carried out in the case of suspected infection based on the available imaging prior to biopsy. For suspected infection, the sensitivity of the pre-interventional imaging was $81 \%, 95 \%-C I$ : [58.1 - 94.6] and the specificity was $44 \%, 95 \%-\mathrm{CI}$ : [31.9-57.6]. If the patient did not receive antibiotic therapy before the CT-guided intervention, the sensitivity was $85 \%, 95 \%-\mathrm{CI}$ : [54.6-98.1] and the specificity was $67 \%, 95 \%-C I$ : [49.0 - 81.4]. In the case of antibiotic therapy prior to biopsy, the sensitivity of the pre-interventional imaging was $75 \%, 95 \%-\mathrm{CI}$ : [35.9-96.8] and the specificity was $15 \%, 95 \%-\mathrm{CI}$ : [4.2-33.7].

The results of the performed biopsies resulted in a change of the therapeutic management, such as operation, chemotherapy or pathogen-specific antibiotic therapy, in approximately one half of all patients (52.3\%). In $43.5 \%$ of the cases, there was no change in patient management based on the result of the pathological or microbiological analysis and in $4.2 \%$ of all cases follow-up did not reveal information concerning patient management.

\section{Discussion}

$\nabla$

We could confirm a high diagnostic accuracy rate of CT-guided biopsies in our cohort and demonstrate that the diagnostic accuracy was slightly higher in microbiological analysis than in histological analysis. Previous studies showed that the diagnostic accuracy of CT-guided biopsies varied from 70 - $93 \%$ [4, 7-10]. A reason for the marginal difference observed in our study could be that all of the infectious lesions that underwent microbiological analysis were lytic or partially liquid whereas some of the malignant lesions had a pure blastic appearance. Lytic lesions are known to have a higher accuracy rate compared to sclerotic lesions $[11,12]$. Most likely it is more difficult to retrieve an adequate sample from sclerotic bone lesions due to the consistency. Sclerotic lesions are mainly composed of eburnated bone with only small areas of bone marrow with a few cell clusters which can hinder analysis [13]. Kattaparum et al. reported minor success when smaller-sized biopsy systems were used [14]. The core needles we used ranged between $3 \mathrm{~mm}$ and $4 \mathrm{~mm}$, which was obviously big enough to avoid crush artifacts and led to a diagnostic success rate close to that of open biopsy.

Generally, diagnostic accuracy has been reported to be higher in the thoracic spine, lumbar spine and sacrum, while the cervical spine has the lowest accuracy [6]. We did not observe significant differences in the diagnostic accuracy and the anatomical level. However, we have to emphasize that the results for the cervical spine in this study were based on a very small group of patients (2/214). There are several reasons why CT-guided biopsy can be unsuccessful, e.g. failure to biopsy the target lesion, failure to collect material sufficient for analysis and inability to make a definitive diagnosis due to nonspecific histological characteristics or the presence of necrosis $[4,7,15]$.

Imaging methods are indispensable in the screening, detection and characterization of lesions of the spine. In most cases, the combination of CT and MRI is able to assess spine lesions and to establish a 
diagnosis. CT, which was available in all cases prior to the biopsy in our study, reveals late osseous destruction. In earlier stages findings may resemble changes of degenerative processes or findings may be completely absent. This is why an additional MRI is required in most cases. MRI is known to be the more sensitive imaging technique to detect bone metastases when compared to CT and planar skeletal scintigraphy [16]. Specificity can be improved by additional sequences like diffusion-weighted images (DWI) and chemical shift imaging [17]. The sensitivity of MRI for vertebral osteomyelitis is reported between $76 \%$ and $100 \%$, and the specificity between $65 \%$ and $96 \%$ [18]. Unfortunately in our study a pre-biopsy MRI was not available in all cases (183/214). In other cases MRI was not performed or was performed without intravenous contrast medium. In addition, the field strength varied from $1.5 \mathrm{~T}$ to $3 \mathrm{~T}$. The moderate sensitivity and the specificity of pre-biopsy imaging in the case of suspected primary tumor or metastatic bone lesion in our study indicates that CT-guided biopsies are necessary for the management and prognosis of patients with bone lesions within the vertebral column. In the case of suspected infection, Sehn and Giliula reported a success rate for identifying a causative pathogen of $30.4 \%$ whereas Garg et al. observed a success rate of $19 \%[19,20]$. The reported data are comparable to the results of our study, as we could detect a causative pathogen in $25 \%$ of the samples. The difference of only $4 \%$ in our study between the patients who received antibiotic therapy and the patients who did not confirms that, apart from the generally low success rate, antibiotic therapy should not be considered as a reason for not performing CT-guided biopsy in the case of suspected infection. In a review of the literature, Cheung et al. reported staphylococcus and streptococcus as being responsible for more than $50 \%$ of vertebral osteomyelitis [21]. Our results confirm these findings because we observed 9/21 positive samples yielding staphylococcus. Therefore, empirical antibiotic therapy should target this pathogen.

In the present study most of the biopsies were performed in the lumbar spine $(57.5 \%)$ followed by the thoracic spine $(35.1 \%)$. Only 2 biopsies were performed in the cervical spine, which were the only manifestation in these patients. Due to the relatively high risk of nerve and spinal cord injury, the duration of biopsies performed in the cervical spine was much longer than biopsies at other anatomical levels like the lumbar spine. We observed a strong correlation between the anatomical level and the biopsy duration following the rule that the closer to the sacrum the faster the biopsy was carried out ( $\bullet$ Fig. 1 ). The risk of percutaneous spine biopsies has been estimated at different anatomical levels. The types and incidence of complications depended on the anatomical level and the type of needle used [22 -24]. More recent studies report that complication rates are negligible, as they are very low. For instance, Rimondi et al. described 22 complications in 2027 CT-guided biopsies, which represents a complication rate of $1.1 \%$ [25]. For comparison in open biopsy the complication rate may be as high as $16 \%$ [26]. The very low complication rate observed in our study was in accordance with the recent data in the literature. The low rate of complications compared to initial studies is due to the possibility of pre-biopsy planning of the approach using CT and MRI, which offer excellent imaging of anatomical structures. Furthermore, the risk of complications depends on the chosen approach. In the present study the transpedicular approach was most commonly performed. Less frequently the posterolateral approach was chosen ( $\bullet$ Fig. 2 ). The transcostovertebral approach was not applied, as it is known to have a significant risk of injury to the costovertebral joint. The accuracy of biopsies obtained using the transpedicular and posterolateral approach was found to be similar in recent studies [27].

There are some limitations of our study that need to be discussed. Preinterventionally available imaging is usually CT. An MRI examination was available prior to biopsy in only $85.5 \%$ of all cases and in some cases $(n=23)$ the MRI scan was acquired without contrast medium, which may explain the moderate sensitivity and specificity of pre-biopsy imaging in our study compared to other recent reports. In addition, chemical shift imaging and diffusion-weighted imaging which are nowadays widely performed to differentiate secondary bone tumors like myeloma and metastases were not available in the early years of our evaluation. Moreover, our study did not evaluate CT and MRI separately. Both were defined as "pre-biopsy imaging". Although it was not the principle issue of our investigation, we conclude that the moderate sensitivity and specificity of the pre-biopsy imaging in our study may be improved when reevaluated in a prospective study with an independent evaluation of CT and MR under similar conditions.

\section{Conclusion \\ $\checkmark$}

CT-guided percutaneous biopsy of the spine is an important tool in the evaluation of suspicious spine lesions both in the case of malignancy and in the case of infection with a high accuracy rate and low risk of complications. It is essential to plan subsequent management and treatment of the patient. The relatively low yield of microorganisms recovered from the CT-guided biopsies in the case of infection in our study confirms the findings of previous studies. Interestingly, our data shows that the pathogen recovery rate is not significantly affected by pre-biopsy antibiotic therapy.

\section{Clinical Relevance}

$>$ CT-guided spine biopsy is an accurate procedure and changed patient management in about $50 \%$ of cases.

$>\mathrm{CT}$ and contrast-enhanced MRI should be available before performing a CT-guided biopsy.

$>$ CT-guided biopsy should be performed in case of infection to isolate an underlying pathogen and in case of malignancy to confirm diagnosis.

In case of infection biopsy can be performed even if antibiotic therapy has been started.

\section{Literature}

1 Mankin HJ, Lange TE, Spanier SS et al. The hazard of biopsy in patients with malignant primary bone and soft-tissue tumors. J Bone Joint Surgery AM 1982; 64: 1121-1127

2 Mankin HJ, Mankin CJ, Simon MA et al. The hazard of biopsy, revisited. J Bone Joint Surgery AM 1996; 78: 656-663

3 Lis E, Bilsky MH, Pisinski L et al. Percutaneous CT-guided biopsy of osseous lesion of the spine in patients with known or suspected malignancy. Am J Neuroradiol 2004; 25: 1583 - 1588

4 Puri A, Ahingade V, Agarwal $M$ et al. CT-guided percutaneous core needle biopsy in deep seated musculoskeletal lesions: a prospective study of 128 cases. Skeletal Radiol 2006; 35: 138-143 
5 Huang AJ, Halpern EF, Rosenthal DI et al. Incidence of delayed complications following percutaneous CT-guided biopsy of bone and soft tissue lesions of the spine and extremities: A 2-year prospective study and analysis. Skeletal Radiol 2013; 42: 61-68

6 Rimondi E, Staals EL, Errani C et al. Percutaneous CT-guided biopsy of the spine: results of 430 biopsies. Eur Spine J 2008; 17: 975-981

7 Hau A, Kim I, Kattapuram S et al. Accuracy of CT-guided biopsies in 359 patients with musculoskeletal lesions. Skeletal Radiol 2002; 31: 349 353

8 Issakov J, Flusser G, Kollendar Y et al. Computed tomography-guided core needle biopsy for bone and soft tissue tumors. Isr Med Assoc J 2003; 5: $28-30$

9 Madhavan VP, Smile SR, Chandra SS et al. Value of core needle biopsy in the diagnosis of soft tissue tumours. Indian J Pathol Microbiol 2002; 45: $165-168$

10 Yang YJ, Damron TA. Comparison of needle core biopsy and fine needle aspiration for diagnostic accuracy in musculoskeletal lesions. Arch of Pathol Lab Med 2004; 128: 759-764

11 Fraser-Hill MA, Renfrew DL. Percutaneous needle biopsy of musculoskeletal lesions. 1. Effective accuracy and diagnostic utility. Am J Roentgenol 1992; 158: 809-812

12 Jelinek JS, Murphey MD, Welker JA et al. Diagnosis of primary bone tumors with image-guided percutaneous biopsy: experience with 110 tumors. Radiology 2002; 223: 731-737

13 Vieillard MH, Boutry N, Chastanet P et al. Contribution of percutaneous biopsy to the definite diagnosis in patients with suspected bone tumor. Joint Bone Spine 2005; 72: 53-60

14 Kattapuram SV, Khurana JS, Rosenthal DI. Percutaneous needle biopsy of the spine. Spine 1992; 17: $561-564$

15 Dupuy DE, Rosenberg AE, Punyaratabandhu T et al. Accuracy of CTguided needle biopsy of musculoskeletal neoplasms. Am J Roentgenol 1998; $171: 759-762$
16 Heindel $W$, Gübitz R, Vieth $V$ et al. The diagnostic imaging of bone metastases. Dtsch Arztebl Int 2014; 111: 741 -747. DOI: 10.3238/arztebl.2014.0741

17 Ghanem N, Altehoefer C, Högerle S et al. Comparative diagnostic value and therapeutic relevance of magnetic resonance imaging and bone marrow scintigraphy in patients with metastatic solid tumors of the axial skeleton. Eur J Radiol 2002; 43: 256-261

18 Matowe L, Gilbert FJ. How to synthesize evidence for imaging guidelines. Clin Radiol 2004; 59: 63-68

19 Sehn JK, Gilula LA. Percutaneous needle biopsy in diagnosis and identification of causative organisms in cases of suspected vertebral osteomyelitis. Eur J Radiol 2012; 81: 940-946

20 Garg V, Kosmas C, Young PC et al. Computed tomography-guided percutaneous biopsy for vertebral osteomyelitis: a department`s experience. Neurosurg Focus 2014; 37: E10

21 Cheung WY, Luk KD. Pyogenic spondylitis. Int Orthop 2012; 36: 397 404

22 Bender CE, Berquist TH, Wold LE. Imaging-assisted percutaneous biopsy of the thoracic spine. Mayo Clin Proc 1986; 61: 942-950

23 Laredo JD, Bard M. Thoracic spine: percutaneous trephine biopsy. Radiology 1986; 160: 485-489

24 Renfrew DL, Whitten CG, Wiese JA et al. CT-guided percutaneous transpedicular biopsy of the spine. Radiology 1991; 180: 574-576

25 Rimondi E, Rossi G, Bartalena T et al. Percutaneous CT-guided biopsy of the musculoskeletal system: results of 2027 cases. Eur J Radiol 2011; 77: $34-42$

26 Welker JA, Henshaw RM, Jelinek J et al. The percutaneous needle biopsy is safe and recommended in the diagnosis of musculoskeletal masses. Cancer 2000; 89: 2677-2686

27 Hao DJ, Sun HH, He BR et al. Accuracy of CT-guided biopsies in 158 patients with thoracic spinal lesions. Acta Radiol 2011; 52: 1015-1019 